crossings of coastal Douglas-fir. Female PoP x POLLEN PoP effects accounted for no variation in DBH21 (Table 2).

\section{Conclusions}

The WWA study suggests that broad-sense GE effects at the population level are not particularly important for coastal Douglas-fir growing across low-elevation sites in western Washington State through 21 years.

The narrow-sense interaction of FEMALE PARENT (POP) $x$ REGION accounted for no variation in DBH21. The other narrow-sense GE effect of FEMALE PARENT (PoP) $\mathrm{x}$ TEST (REGION) was the most important interaction in this study. However, the magnitude of this interaction does not appear sufficient to prevent reliable selection of coastal Douglas-fir for strong stable performance across the low elevation environments studied.

\section{Acknowledgements}

With many thanks to current and past members of the Tree Improvement Team at Weyerhaeuser including especially: Jerry Chapman, Jess DANiels, MARK HefFner, Gary Helland, Ed Herold, Jim Reno and Roy STONECYPHER who have been responsible for the installation, diligent long-term care and maintenance of these study sites and the measurement and management of the ensuing high quality data.

\section{Literature Cited}

CAMPBElL, R. K. (1986): Mapped genetic variation of Douglas-fir to guide seed transfer in southwest Oregon. Silvae Genet. 35: 85-95.

DEAN, C. A. (2007): Genotype and population performances and their interactions for growth of coastal Douglas-fir in western Washington. For. Sci. 53: 463-472.

Gilmour, A. R., B. J. Gogel, B. R. Cullis and R. ThompSON (2006): ASREML User Guide Release 2.0 VSN International Ltd, Hemel Hempstead, HP1 1ES, UK.

Matheson, A. C. and P. P. CotTerill (1990): Utility of genotype $\mathrm{x}$ environment interactions. For. Ecol. Manage. 30: $159-174$.

Silen, R. R. and J. G. WheAT (1979): Progressive tree improvement program in coastal Douglas-fir. J. For. 77: $78-83$.

StonecypheR, R. W. (1990): Assessing effects of seed transfer for selected parents of Douglas-fir: Experimental methods and early results. In: Proc. of Joint Meet. of Western Forest Genetics Association and IUFRO Working Parties S2.02-05,06,12 and 14. Olympia, WA.

White, T. L. and K. K. ChInG (1985): Provenance study of Douglas-fir in the Pacific Northwest region. IV. Field performance at age 25 years. Silvae Genet. 34: 84-90.

\title{
Growth Rhythm Parameters as Components of Hybrid Vigour in Young Seedlings of Hybrid Larch (Larix decidua $x$ L. kaempferi)
}

\author{
By LuC E. PÂQUES*) \\ INRA-UR588, Unité Amélioration, Génétique et Physiologie des arbres forestiers, \\ F-45160 Orléans (France)
}

(Received $22^{\text {th }}$ November 2007)

\begin{abstract}
Heterosis for growth traits was investigated on 2-yrold seedlings from related intra- and inter-specific progenies collected in hybridisation seed orchards combining Larix decidua (EL) and L. kaempferi (JL). Following taxa identification, seedlings phenology and growth were observed over a complete growing season in two experiments. Start, cessation, duration and rates of growth for the different taxa were explored in relation to hybrid vigour. Variable levels of heterosis were observed, depending on the genetic background of the parental species, the species over which superiority was
\end{abstract}

\footnotetext{
*) Tel. +332 384178 21, Fax: +33 2384178 79, E-mail: paques@ orleans.inra.fr
}

evaluated, environmental conditions and the traits considered. While significant and consistent differences have been observed between hybrids and their related EL progenies for phenological growth traits, a better timing of the growth rhythm over the growing season together with a greater growth efficiency allowed for a consistently positive heterosis over EL. The situation appeared more complex with JL as heterosis could be either positive or negative. Besides the high variation in heterosis levels, the way heterosis for height built up over the growing season seemed also to be variable according to genetic backgrounds: cumulative constant superiority of the hybrid for growth rhythms along the growing season or greater growth rates during discrete periods of time.

Key words: heterosis, phenology, growth, hybrid larch, Larix. 


\section{Introduction}

Interspecific hybridisation is commonly exploited for larch (Larix) breeding. Indeed artificial crossing is successful for many species combinations and several hybrids have found a commercial value for reforestation. That is the case in Europe for the hybrids between the European (Larix decidua) and the Japanese (L. kaempferi) larches.

Major interests of interspecific hybridisation include the possibility to combine favourable complementary traits from both parental species and to take advantage of hybrid vigour. Hybrid vigour or heterosis sensu stricto expresses the superiority of the hybrid over the mean of its parents (or over its best parent) for a given trait. While the superiority of $L$. decidua $\mathrm{x} L$. kaempferi hybrids over either the European or the Japanese larch has been well documented for several traits (PÂQUES, 2002), very few studies have investigated hybrid vigour per se. Indeed, the study of hybrid vigour commonly requires related intra- and inter-specific pedigrees such as found in more sophisticated mating designs like diallel mating plans. These are particularly costly and timeconsuming to construct for larches because of constraints imposed by poor pollen and seed yields, a quite typical problem for larch (BONNET-MASIMBERT et al., 1998).

As a result, the genetic basis of heterosis is poorly understood and documented in forest trees and for larch in particular. As well, very few studies have investigated the structural and physiological basis of hybrid larch superiority. MATYSSEK and SCHUlze $(1987 a, b)$ on one side have investigated the roles of gas exchange responses, of leaf characteristics and of tree architecture on so-called heterosis of a 33-yr-old Larix decidua $\mathrm{x}$ L. kaempferi hybrid combination. On the other side, Baltunis and GREENwOOD (1999) have explored the link between several lateral shoot elongation parameters and hybrid superiority in various interspecific hybrids combining $L$. decidua, L. kaempferi and L. laricina. While major results have been obtained showing for example the complementation of some morphological traits, they are either based on a limited number of trees per taxa (1-2) and hybrid combinations (1) or they relate to the superiority of hybrids over non-related parents rather than to heterosis per se.

In this study, we will compare several phenological parameters and annual growth patterns among young plants of the hybrid and related progenies of pure larch species (L. decidua, L. kaempferi) and we will investigate their relationship with hybrid vigour.

\section{Material and Methods}

\section{Plant material}

Two year-old seedlings were used for this study. They derived from two nursery experiments established during the springs 2000 and 2004 respectively, with one-yrold bare-root seedlings. Each experiment included progenies from six seed lots, representing altogether progenies from a total of ten European commercial hybridisation seed orchards (Table I). These represent various types of orchards in terms of genetic composition (origin and number of clones), establishment design and way of crossing and of cone collection. More details on plant production and experimental designs used in the nursery can be found in PÂQUES et al. (2006).

Due to the way seedlots were produced (open-pollination) and because of a more than frequent partial mismatching of flowering phenology between the two parental species in these orchards, progenies from hybridisation orchards usually represent mixtures of plants from the two to three taxa: hybrids, pure European larches and/or Japanese larches (ACHERÉ et al., 2002; ACHERÉ et al., 2004).

Taxa of individual trees were identified from needles collected during summer-time with diagnostic cytoplasmic DNA markers developed by ACHERÉ et al. (2004). Details can be found in PÂQUES et al. (2006). The proportion of hybrids and of pure species is shown in Table I for each plant lot. Thus, we took advantage of this mixture of taxa in the different plant lots to compare their intra- and inter-specific progenies based on a common

Table I. - Description of seed orchard plant lots.

\begin{tabular}{|c|c|c|c|c|c|c|}
\hline Code & Components ${ }^{1)}$ & Crop year & $\begin{array}{c}\text { Proportion } \\
\text { of EL } \\
(\%)\end{array}$ & $\begin{array}{c}\text { Proportion } \\
\text { of JL } \\
(\%)\end{array}$ & $\begin{array}{c}\text { Hybrid } \\
\text { purity } \\
(\%) \\
\end{array}$ & Experiment \\
\hline SO1 & $1 \mathrm{EL} \times 1 \mathrm{FS}^{2)} \mathrm{JL}$ & 1992 & 28.4 & 0 & 71.6 & 1 \\
\hline $\mathrm{SO} 2.1$ & $15 \mathrm{JL} \times 15 \mathrm{EL}^{3)}$ & 1987 & 27.0 & 32.0 & 41.3 & 1 \\
\hline $\mathrm{SO} 2.2$ & $15 \mathrm{JL} \times 15 \mathrm{EL}^{3)}$ & 1998 & 29.0 & 23.0 & 48.0 & 1 \\
\hline $\mathrm{SO} 2.3$ & $\overline{15 \mathrm{JL}} \times \overline{15 \mathrm{EL}}$ & 1983 & 3.9 & 72.6 & 23.5 & 2 \\
\hline $\mathrm{SO} 3$ & $\overline{1 \mathrm{EL}} \times 1 \mathrm{JL}$ & 1983 & 82.0 & 1.0 & 17.0 & 1 \\
\hline SO4 & $12 \mathrm{EL} \times 28 \mathrm{JL}$ & 1996 & 22.3 & 0 & 77.7 & 1 \\
\hline SO5 & $33 \mathrm{JL} \times 33 \mathrm{EL}$ & 1996 & 0 & 77.6 & 22.4 & 1 \\
\hline SO6 & $20 \mathrm{JL} \times 20 \mathrm{EL}$ & 1996 & 0 & 91.8 & 8.2 & 2 \\
\hline SO7 & $\overline{1 \mathrm{EL}} \times 5 \mathrm{JL}$ & 1996 & 15.9 & 0 & 84.1 & 2 \\
\hline SO8 & $\overline{1 \mathrm{JL}} \times 4 \mathrm{EL}$ & 1993-2002 & 0 & 26.2 & 73.8 & 2 \\
\hline SO9 & $1 \mathrm{EL} \times 261 \mathrm{JL}$ & 1996 & 12.5 & 0 & 87.5 & 2 \\
\hline SO10 & $1 \mathrm{EL} \times 1 \mathrm{FS} J \mathrm{~J}$ & 1999 & 8.2 & 0 & 91.8 & 2 \\
\hline
\end{tabular}

1) Species underlined $=$ mother species $(\mathrm{EL}=$ European larch $/ \mathrm{JL}=$ Japanese larch $)$.

2) FS means full-sib progeny.

3) Exceptionally, seedlots have been collected on both parents for that study. 
genetic background within a given orchard. Unexpected taxa were found in orchards SO2.3 (EL) and SO3 (JL) progenies; their origin is unknown but it could be the result of errors during cone collection, mislabelling of ramets at plantation or graft rejection. Those seedlings were discarded before further analysis.

\section{Measurements}

During their second growing season, growth increment of the terminal shoot was weekly recorded on each plant following terminal bud flushing and until bud-set. In the first experiment, 17 measures were recorded from June 14 up to October 5, 2000. In the second one, 14 measures were recorded from June 28 up to October 14, 2004. Total height (H2) and root-collar diameter (D2) were finally measured at the end of the growing season.

\section{Data analysis}

The shoot growth increment curve of each tree over the second growing year was fitted using individual shoot growth data based on the following Weibull growth model:

$$
\begin{aligned}
& \mathrm{H}(\mathrm{t})=\mathrm{p}_{1}\left(1-\mathrm{e}^{-\mathrm{b}}\right) \text { where } \mathrm{b}=\left(\mathrm{p}_{2}\left(1-\mathrm{p}_{3}\right) * \mathrm{t} / \mathrm{p} 1\right) /\left(1-\mathrm{p}_{3}\right) \\
& \text { Where } \mathrm{H}(\mathrm{t})=\text { shoot elongation as a function of time } \\
& \quad(\mathrm{cm}), \\
& \mathrm{t}=\text { time }(\text { in days; day } 1=\text { April } 1), \\
& \mathrm{p}_{1}=\text { asymptote corresponding to the total } \\
& \quad \text { elongation of the growth cycle, } \\
& \mathrm{p}_{2}=\text { parameter linked to the maximum } \\
& \quad \text { growth increment, } \\
& \mathrm{p}_{3}=\text { curve pattern parameter. }
\end{aligned}
$$

These parameters were calculated for each tree by the nonlinear regression model (nls2) using S-Plus. From these mathematical parameters, several biological parameters could be evaluated, namely:

$\mathrm{T} 0, \mathrm{TF}=$ dates when $5 \%, 95 \%$ respectively of total shoot length increment is achieved, (in days since April 1),

$\mathrm{TI}=$ date when the growth rate is maximum, (in days since April 1),

$\mathrm{DU}=\mathrm{TF}-\mathrm{T} 0=$ total number of days of shoot elongation,

MaxI = maximum rate of elongation,

LRI = relative length of shoot achieved at date TI.

Periodic shoot length measurements were also used to compute daily shoot growth current increments as well as the mean daily increment over the $2^{\text {nd }}$ growing period using the total shoot length and the total number of days of shoot elongation (DU).

A simple stem volume index (V2) was computed from total height and root-collar diameter at the end of the $2^{\text {nd }}$ growing season as V2 $=\left(\pi \mathrm{D} 2^{2} \cdot \mathrm{H} 2\right) / 4$.

For each experiment, individual tree data were then adjusted to significant block (fixed) effects following a separate two-way analysis of variance including block and seed orchard as mains factors. A second set of oneway analysis of variance was then conducted for each orchard to test the significance of taxa effects. When all 3 taxa were present among the progeny of an orchard, a Scheffé-test was used to compare taxa means.

Heterosis was then computed as (HL-EL)/EL and as (HL-JL)/JL with EL, JL and HL being respectively the mean performances of the European (EL) and/or Japan-

Table II.a. - Means of traits characteristics per taxa: experiment 1. (coefficient of variation between brackets, in bold, when the pure species is significantly different from hybrid at $5 \%$ ).

Seed collected on EL

\begin{tabular}{lccccccc}
\hline Seed orchard & & \multicolumn{2}{c}{ SO1 } & \multicolumn{2}{c}{ SO3 } & \multicolumn{2}{c}{ SO4 } \\
& & EL & HL & EL & HL & EL & HL \\
ni & & 18 & 50 & 72 & 16 & 21 & 80 \\
\hline Total height & $(\mathrm{cm})$ & $\mathbf{3 5 . 8}$ & 51.4 & $\mathbf{3 5 . 1}$ & 48.8 & $\mathbf{4 5 . 5}$ & 55.6 \\
& & $\mathbf{( 3 9 \% )}$ & $(23 \%)$ & $\mathbf{( 2 9 \% )}$ & $(22 \%)$ & $(\mathbf{2 7 \%})$ & $(25 \%)$ \\
Shoot length increment & $(\mathrm{cm})$ & $\mathbf{2 1 . 2}$ & 28.8 & $\mathbf{2 0 . 2}$ & 28.9 & 26.1 & 28.7 \\
& & $\mathbf{( 4 9 \% )}$ & $(40 \%)$ & $\mathbf{3 9 \%}$ & $(31 \%)$ & $(40 \%)$ & $(42 \%)$ \\
Mean daily shoot growth & $(\mathrm{mm})$ & $\mathbf{1 . 7}$ & 2.8 & $\mathbf{1 . 6}$ & 2.8 & $\mathbf{2 . 2}$ & 2.9 \\
increment & & $\mathbf{( 6 6 \% )}$ & $(39 \%)$ & $\mathbf{( 4 6 \% )}$ & $(38 \%)$ & $(\mathbf{3 7 \%} \%$ & $(43 \%)$ \\
\hline Diameter & $(\mathrm{mm})$ & $\mathbf{9 . 9}$ & 13.9 & $\mathbf{7 . 3}$ & 11.1 & $\mathbf{9 . 3}$ & 12.6 \\
& & $\mathbf{( 3 9 \% )}$ & $(24 \%)$ & $\mathbf{( 3 6 \% )}$ & $(22 \%)$ & $(\mathbf{2 6 \%})$ & $(29 \%)$ \\
\hline Volume & $\left(\mathrm{cm}^{3}\right)$ & $\mathbf{4 0 . 7}$ & 89.5 & $\mathbf{1 8 . 2}$ & 53.3 & $\mathbf{3 6 . 0}$ & 85.2 \\
& & $\mathbf{( 1 5 3 \% )}$ & $(65 \%)$ & $\mathbf{( 1 0 1 \% )}$ & $(60 \%)$ & $\mathbf{( 7 3 \% )}$ & $(91 \%)$ \\
\hline
\end{tabular}

Seed collected on JL and EL (SO2.1 \& 2) or on JL only (SO5)

\begin{tabular}{lccccccccc}
\hline Seed orchard & & & SO2.1 & & \multicolumn{3}{c}{ SO2.2 } & \multicolumn{3}{c}{ SO5 } \\
ni & & EL & JL & HL & EL & JL & HL & JL & HL \\
& & 28 & 33 & 55 & 40 & 28 & 60 & 42 & 17 \\
\hline Total height & $(\mathrm{cm})$ & 51.0 & 50.7 & 52.3 & 65.5 & 55.7 & 63.9 & 44.4 & 40.3 \\
& & $(23 \%)$ & $(28 \%)$ & $(32 \%)$ & $(22 \%)$ & $(23 \%)$ & $(22 \%)$ & $(30 \%)$ & $(30 \%)$ \\
Shoot length increment & $(\mathrm{cm})$ & 29.1 & 23.1 & 28.8 & 37.0 & $\mathbf{2 6 . 0}$ & 32.9 & 20.7 & 19.2 \\
& & $(27 \%)$ & $(55 \%)$ & $(45 \%)$ & $(22 \%)$ & $(\mathbf{4 4} \%)$ & $(33 \%)$ & $(54 \%)$ & $(51 \%)$ \\
Mean daily shoot growth & $(\mathrm{mm})$ & 2.3 & 2.5 & 2.8 & 3.0 & 2.7 & 3.0 & 2.2 & 1.9 \\
increment & & $(31 \%)$ & $(59 \%)$ & $(50 \%)$ & $(23 \%)$ & $(42 \%)$ & $(35 \%)$ & $(51 \%)$ & $(46 \%)$ \\
\hline Diameter & $(\mathrm{mm})$ & 11.2 & 12.2 & 12.6 & 12.9 & 12.8 & 13.3 & 11.3 & 10.1 \\
& & $(25 \%)$ & $(28 \%)$ & $(35 \%)$ & $(20 \%)$ & $(23 \%)$ & $(26 \%)$ & $(31 \%)$ & $(30 \%)$ \\
\hline Volume & $\left(\mathrm{cm}^{3}\right)$ & 56.7 & 71.2 & 87.7 & 91.4 & 83.2 & 102.5 & 56.7 & 40.4 \\
& & $(58 \%)$ & $(80 \%)$ & $(97 \%)$ & $(52 \%)$ & $(60 \%)$ & $(61 \%)$ & $(89 \%)$ & $(84 \%)$ \\
\hline
\end{tabular}


Table II.b. - Means of traits characteristics per taxa: experiment 2. (coefficient of variation between brackets, in bold, when the pure species is significantly different from hybrid at $5 \%$ ).

Seed collected on EL

\begin{tabular}{lccccccc}
\hline \multicolumn{2}{c}{ Seed orchard } & \multicolumn{2}{c}{ SO7 } & \multicolumn{2}{c}{ SO9 } & \multicolumn{2}{c}{ SO10 } \\
\multirow{2}{*}{ ni } & & EL & HL & EL & HL & EL & HL \\
& & 17 & 86 & 11 & 72 & 9 & 94 \\
\hline Total height & $(\mathrm{cm})$ & $\mathbf{4 6 . 4}$ & 62.1 & $\mathbf{5 3 . 7}$ & 70.3 & $\mathbf{3 6 . 2}$ & 58.7 \\
& & $\mathbf{( 3 2} \%)$ & $(21 \%)$ & $\mathbf{( 2 9 \% )}$ & $(22 \%)$ & $\mathbf{( 2 6 \% )}$ & $(24 \%)$ \\
Shoot length increment & $(\mathrm{cm})$ & $\mathbf{3 6 . 2}$ & 48.9 & $\mathbf{4 3 . 2}$ & 55.6 & $\mathbf{2 8 . 7}$ & 46.9 \\
& & $\mathbf{( 3 4 \% )}$ & $(23 \%)$ & $\mathbf{( 3 3 \% )}$ & $(27 \%)$ & $\mathbf{( 2 9 \% )}$ & $(28 \%)$ \\
Mean daily shoot growth & $(\mathrm{mm})$ & $\mathbf{2 . 4}$ & 4.5 & $\mathbf{3 . 0}$ & 5.0 & $\mathbf{1 . 8}$ & 4.0 \\
increment & & $\mathbf{( 5 0 \% )}$ & $(27 \%)$ & $\mathbf{( 3 8 \% )}$ & $(30 \%)$ & $\mathbf{( 3 3 \% )}$ & $(31 \%)$ \\
\hline Diameter & $(\mathrm{mm})$ & $\mathbf{9 . 8}$ & 13.5 & $\mathbf{1 0 . 9}$ & 14.0 & $\mathbf{9 . 6}$ & 12.4 \\
& & $\mathbf{( 2 0 \% )}$ & $(20 \%)$ & $\mathbf{( 3 2 \% )}$ & $(18 \%)$ & $\mathbf{( 2 4 \% )}$ & $(20 \%)$ \\
\hline Volume & $\left(\mathrm{cm}^{3}\right)$ & $\mathbf{4 0 . 3}$ & 97.0 & $\mathbf{6 1 . 5}$ & 116.4 & $\mathbf{2 9 . 6}$ & 78.2 \\
& & $\mathbf{( 7 1 \% )}$ & $(48 \%)$ & $\mathbf{( 7 7 \% )}$ & $(52 \%)$ & $\mathbf{( 6 3 \% )}$ & $(54 \%)$ \\
\hline
\end{tabular}

Seed collected on JL

\begin{tabular}{lccccccc}
\hline Seed orchard & \multicolumn{2}{c}{ SO2.3 } & \multicolumn{2}{c}{ SO6 } & \multicolumn{2}{c}{ SO8 } \\
ni & & JL & HL & JL & HL & JL & HL \\
& & 68 & 27 & 98 & 9 & 14 & 49 \\
\hline Total height & $(\mathrm{cm})$ & $\mathbf{5 8 . 9}$ & 72.0 & 76.7 & 78.6 & $\mathbf{3 3 . 2}$ & 63.5 \\
& & $\mathbf{( 2 8 \% )}$ & $(22 \%)$ & $(19 \%)$ & $(18 \%)$ & $\mathbf{( 4 4 \% )}$ & $(35 \%)$ \\
Shoot length increment & $(\mathrm{cm})$ & $\mathbf{4 6 . 7}$ & 59.2 & 58.7 & 58.9 & $\mathbf{2 7 . 5}$ & 47.5 \\
& & $\mathbf{( 3 2 \% )}$ & $(24 \%)$ & $(23 \%)$ & $(22 \%)$ & $\mathbf{( 4 8 \% )}$ & $(43 \%)$ \\
Mean daily shoot growth & $(\mathrm{mm})$ & 3.0 & 4.5 & 5.2 & 4.6 & $\mathbf{2 . 5}$ & 4.3 \\
increment & & $(27 \%)$ & $(29 \%)$ & $(24 \%)$ & $(20 \%)$ & $\mathbf{( 4 6 \% )}$ & $(35 \%)$ \\
\hline Diameter & $(\mathrm{mm})$ & $\mathbf{1 1 . 5}$ & 14.0 & 15.2 & 16.2 & $\mathbf{8 . 6}$ & 13.7 \\
& & $\mathbf{( 2 3 \% )}$ & $(29 \%)$ & $(21 \%)$ & $(19 \%)$ & $\mathbf{( 3 1 \% )}$ & $(26 \%)$ \\
\hline Volume & $\left(\mathrm{cm}^{3}\right)$ & $\mathbf{7 0 . 7}$ & 132.6 & 152.2 & 174.4 & $\mathbf{2 4 . 1}$ & 113.2 \\
& & $\mathbf{( 2 4 \% )}$ & $(77 \%)$ & $(57 \%)$ & $(54 \%)$ & $\mathbf{( 8 5 \% )}$ & $(75 \%)$ \\
\hline
\end{tabular}

ese (JL) and hybrid (HL) larch progenies within each orchard progeny. It was expressed in percent. Hybrid superiority for vigour traits was then related to phenology and growth parameters obtained from the growth model.

\section{Results}

Mean taxa growth at the end of the second growing year

Mean results for taxa within orchards are given in Table II. $a$ for experiment 1 and in Table II.b for experiment 2 .

In experiment 1 , total height of hybrid larch progenies at the end of the second growing season ranged from $40.3 \mathrm{up}$ to $63.9 \mathrm{~cm}$ according to orchards, compared to a range of 35.1-65.5 cm for European larch and of 44.4-55.7 cm for Japanese larch. For root-collar diameter, the range was from $10.1 \mathrm{up}$ to $13.9 \mathrm{~mm}$ for hybrids compared to 7.3-12.9 $\mathrm{mm}$ for EL and 11.3-12.8 $\mathrm{mm}$ for JL. Finally for volume index, it ranged from 53.3-102.5 $\mathrm{cm}^{3}$ for HL, compared to $18.2-91.4 \mathrm{~cm}^{3}$ for EL and to $56.7-83.2 \mathrm{~cm}^{3}$ for JL.

In experiment 2 , a broad variation existed too among orchards and taxa progenies within orchards for all growth traits: for total height, the hybrids ranged from 58.7 up to $78.6 \mathrm{~cm}$ while EL progenies ranged from $36.2-53.7 \mathrm{~cm}$ and JL from $33.2-76.7 \mathrm{~cm}$. For diameter, the range was from $12.4-16.2 \mathrm{~mm}$ for $\mathrm{HL}, 9.6-10.9 \mathrm{~mm}$ for EL and 8.6-15.2 mm for JL. Finally for volume index, it varied from $78.2-174.4 \mathrm{~cm}^{3}$ for HL compared to $29.6-61.5 \mathrm{~cm}^{3}$ for EL and $24.1-152.2 \mathrm{~cm}^{3}$ for JL.
The average height annual increment during the second growing season reached $19.2-32.9 \mathrm{~cm}$ for HL compared to $20.2-37.0 \mathrm{~cm}$ for EL and $20.7-26.0 \mathrm{~cm}$ for $\mathrm{JL}$ in experiment 1 . In experiment 2 , it reached $46.9-59.2 \mathrm{~cm}$ for $\mathrm{HL}, 28.7-43.2 \mathrm{~cm}$ for EL and $27.5-58.7 \mathrm{~cm}$ for JL.

\section{Components of growth phenology during the second growing season}

Four parameters were available from growth modelling: the start (T0) and the end (TF) of shoot elongation, the duration of growth (DU) as well as the time of maximum growth rate (TI). They are summarised in Tables III. $a$ and $b$ respectively for experiments 1 and 2 and illustrated in Figure 1.

\section{Start of growth}

In experiment 1, height growth for EL started on average between 49 and 66 days after April 1 (mid-May first decade of June) according to orchards; for JL, it started at days 86 to 90 (last decade of June) and for HL, at days 74 to 85 (mid-June - last decade of June). For all orchards, EL started shoot elongation earlier (that is 18-25 days) than HL and the difference was statistically significant. JL growth started the latest among the 3 taxa; that was between 8 and nearly 14 days later than HL so that HL was clearly intermediate to EL and JL. Differences between taxa were also significant excepted for SO5.

In experiment 2 , exactly the same trend was observed: HL started growth later than EL (16-25 days later), but earlier than JL (around 1-10 days before). Differences among taxa were significant excepted for SO8. 


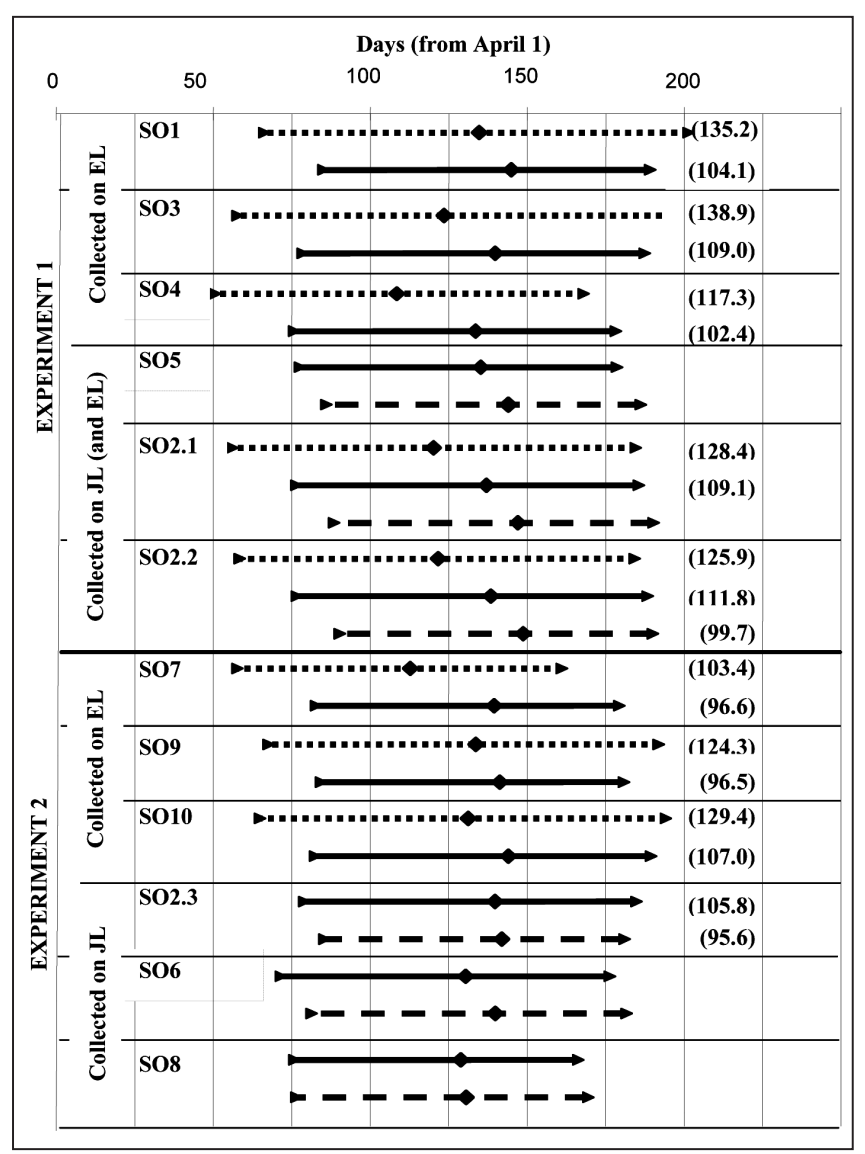

Figure 1. - Average dates when $5 \%$ (T0), maximum rate (TI) and $95 \%$ of elongation (TF) were reached for the different taxa within orchards. (growth duration is indicated between brachets when hybrid differs significantly from parental species).

$(\ldots \ldots . .=\mathrm{EL},-\mathbf{-}=\mathrm{JL},-\longrightarrow=\mathrm{HL})$.

\section{Time for maximum growth rate}

Maximum rate of growth occurred on average in experiment 1 between 107 and 135 days after April 1 for EL, that is between mid-July to mid-August according to orchards; for HL, it occurred from days 132 to 145 (first to last decades of August) and for JL between days 144 and 149, that is in the last decade of August. Within all orchards, EL had its maximum rate of growth 17-26 days before HL and the differences were always significant. As for JL, it occurred 9-10 days later than HL. Differences among taxa were also significant.

In experiment 2 , EL had its maximum growth rate between 113 and 134 days after April 1 (that is from last decade of July to mid-August). For HL, it occurred between 129 and 144 days (first to last decades of August) and for JL, between 131 and 142 days (first two decades of August). Clearly, the maximum growth occurred between 7.6 and 26.8 days later for HL compared to EL and the difference was significant. HL reached its maximum growth rate a bit earlier than JL: from less than 1 day to 9.8 days. The difference was significant for only one orchard.

\section{End of growth}

Ninety-five percents of shoot elongation (TF) were achieved in experiment 1 on average by day 166 up to
201 (mid-September - mid-October) for EL while TF was reached in a range of 177-189 days (last decade of September- first decade of October) for HL. No consistency was found in the relative date of cessation of growth of HL compared to EL. It varied much according to orchards: the hybrid either ceased its growth 9-12 days earlier or -10 days later than EL. For Japanese larch, TF varied between 186-191 days (first decade of October), that was 1.6-7.5 later than HL but the differences between taxa were not significant.

In experiment $2, \mathrm{TF}$ occurred between days 161 and 194 for EL, 166 and 189 for HL and 169 and 182 for JL. Within orchards, HL stopped growing either 4.7-11.1 days earlier or 4.8-18.3 days later than EL and 3.1-5.3 days earlier or 3.8 days later than JL. Differences were most often significant.

\section{Length of the growing season}

Finally, the length of the growing season ranged for EL from 117-139 days and 103-129 days respectively in experiments 1 and 2; from 100-102 and 93-100 days for JL and from 101-112 and 91-107 days for HL. Whatever the orchard, it was always significantly shorter for HL compared to EL: from 14.1 days for SO2.2 up to 31.1 days for SO1 orchards in experiment 1 and from 6.8 (SO7) - 27.8 (SO9) days in experiment 2. Compared to JL, HL had most commonly a longer period of growth (from 1 day for SO5 to 12 days for SO2.2) except for one orchard (SO8) but differences were rarely significant.

\section{Growth rhythm}

Mean daily shoot growth increment (Tables IIa and $b$ )

Over the $2^{\text {nd }}$ season of growth, the mean daily growth increment ranged from $1.6-3.0 \mathrm{~mm} /$ day for EL, $2.2-2.7$ $\mathrm{mm}$ /day for $\mathrm{JL}$ and $1.9-3.0 \mathrm{~mm} /$ day for HL in experiment 1 and from $1.8-3.0 \mathrm{~mm} /$ day for EL, 2.5-5.2 $\mathrm{mm}$ /day for JL and $4.0-5.0 \mathrm{~mm} /$ day for HL in experiment 2. In both experiments within orchards, mean daily increments were higher for HL compared to EL but not significantly for SO2 orchard. Compared to JL, differences were in all but one case not significant.

\section{Maximum rate of growth (Tables III $a$ and $b$ )}

The maximum rates of growth varied between 2.1 and $4.0 \mathrm{~mm}$ /day for EL in experiment 1 and 3.0 to 4.8 $\mathrm{mm}$ /day in experiment 2. For JL, it ranged from 3.4 and $3.8 \mathrm{~mm} /$ day and 3.5 and $7.8 \mathrm{~mm} /$ day respectively in experiments 1 and 2. Finally for HL, maximum growth rate varied between 2.8 and $4.2 \mathrm{~mm}$ /day in experiment 1 and 5.9 and $7.4 \mathrm{~mm}$ /day in experiment 2. Hybrid larch maximum growth rate was always higher than that of EL whatever the orchard; differences were significantly different excepted for SO2 orchard. Compared to JL, it could be either significantly higher (SO8, SO2.3 in experiment 2) or not significantly different.

\section{Current daily shoot growth increment}

In order to better understand when the growth dynamics of taxa changed over the growing season, differences of current shoot growth increments between hybrids and either EL or JL were computed and plotted in Figure 2. 
Table III.a. - Means of traits characteristics per taxa: experiment 1 (coefficient of variation between brackets, in bold, when the pure species is significantly different from hybrid at $5 \%$ ).

\begin{tabular}{|c|c|c|c|c|c|c|c|}
\hline \multirow{2}{*}{\multicolumn{2}{|c|}{ Seed orchard }} & \multicolumn{2}{|c|}{ SO1 } & \multicolumn{2}{|c|}{ SO3 } & \multicolumn{2}{|c|}{ SO4 } \\
\hline & & EL & HL & EL & HL & EL & HL \\
\hline T0 & (days) & $\begin{array}{c}66.1 \\
(22 \%)\end{array}$ & $\begin{array}{c}85.0 \\
(16 \%)\end{array}$ & $\begin{array}{c}57.6 \\
(23 \%)\end{array}$ & $\begin{array}{c}78.4 \\
(14 \%)\end{array}$ & $\begin{array}{c}49.1 \\
(17 \%)\end{array}$ & $\begin{array}{c}74.3 \\
(19 \%)\end{array}$ \\
\hline TI & (days) & $\begin{array}{l}134.6 \\
(6 \%)\end{array}$ & $\begin{array}{l}144.9 \\
(8 \%)\end{array}$ & $\begin{array}{l}123.5 \\
(10 \%)\end{array}$ & $\begin{array}{l}139.7 \\
(5 \%)\end{array}$ & $\begin{array}{l}106.9 \\
(13 \%)\end{array}$ & $\begin{array}{l}132.1 \\
(11 \%)\end{array}$ \\
\hline LRI & $\%$ & $\begin{array}{c}51 \\
(6 \%)\end{array}$ & $\begin{array}{c}55 \\
(4 \%)\end{array}$ & $\begin{array}{c}50 \\
(8 \%)\end{array}$ & $\begin{array}{c}54 \\
(4 \%)\end{array}$ & $\begin{array}{c}50 \\
(4 \%)\end{array}$ & $\begin{array}{c}54 \\
(4 \%)\end{array}$ \\
\hline MaxI & (cm/day) & $\begin{array}{c}0.22 \\
(61 \%)\end{array}$ & $\begin{array}{c}0.39 \\
(38 \%)\end{array}$ & $\begin{array}{c}0.21 \\
(43 \%)\end{array}$ & $\begin{array}{c}0.38 \\
(39 \%)\end{array}$ & $\begin{array}{c}0.29 \\
(35 \%)\end{array}$ & $\begin{array}{c}0.38 \\
(44 \%)\end{array}$ \\
\hline $\mathrm{TF}$ & (days) & $\begin{array}{l}201.4 \\
(9 \%)\end{array}$ & $\begin{array}{l}189.1 \\
(8 \%)\end{array}$ & $\begin{array}{c}196.5 \\
(14 \%)\end{array}$ & $\begin{array}{l}187.4 \\
(5 \%)\end{array}$ & $\begin{array}{l}166.5 \\
(10 \%)\end{array}$ & $\begin{array}{l}176.7 \\
(10 \%)\end{array}$ \\
\hline DU & (days) & $\begin{array}{l}135.2 \\
(21 \%)\end{array}$ & $\begin{array}{c}104.1 \\
(20 \%)\end{array}$ & $\begin{array}{r}138.9 \\
(26 \%)\end{array}$ & $\begin{array}{c}109.0 \\
(17 \%)\end{array}$ & $\begin{array}{l}117.3 \\
(12 \%)\end{array}$ & $\begin{array}{c}102.4 \\
(16 \%)\end{array}$ \\
\hline
\end{tabular}

Seed collected on JL and EL (SO2.1 \& 2) or on JL only (SO5)

\begin{tabular}{|c|c|c|c|c|c|c|c|c|c|}
\hline \multirow{2}{*}{\multicolumn{2}{|c|}{ Seed orchard }} & \multicolumn{3}{|c|}{ SO2.1 } & \multicolumn{3}{|c|}{ SO2.2 } & \multicolumn{2}{|c|}{ SO5 } \\
\hline & & EL & $\mathbf{J L}$ & HL & EL & $\mathbf{J L}$ & HL & $\mathbf{J L}$ & $\mathbf{H L}$ \\
\hline T0 & (days) & $\begin{array}{c}56.7 \\
(18 \%)\end{array}$ & $\begin{array}{c}89.1 \\
(16 \%)\end{array}$ & $\begin{array}{c}77.0 \\
(19 \%)\end{array}$ & $\begin{array}{c}58.3 \\
(17 \%)\end{array}$ & $\begin{array}{c}90.2 \\
(16 \%)\end{array}$ & $\begin{array}{c}76.6 \\
(17 \%)\end{array}$ & $\begin{array}{c}86.0 \\
(18 \%)\end{array}$ & $\begin{array}{c}77.6 \\
(22 \%)\end{array}$ \\
\hline TI & (days) & $\begin{array}{c}120.8 \\
(11 \%)\end{array}$ & $\begin{array}{l}147.6 \\
(4 \%)\end{array}$ & $\begin{array}{l}137.6 \\
(9 \%)\end{array}$ & $\begin{array}{l}121.6 \\
(9 \%)\end{array}$ & $\begin{array}{l}148.6 \\
(8 \%)\end{array}$ & $\begin{array}{l}138.4 \\
(7 \%)\end{array}$ & $\begin{array}{l}143.9 \\
(8 \%)\end{array}$ & $\begin{array}{l}135.2 \\
(12 \%)\end{array}$ \\
\hline LRI & $\%$ & $\begin{array}{c}51 \\
(4 \%)\end{array}$ & $\begin{array}{c}56 \\
(5 \%)\end{array}$ & $\begin{array}{c}54 \\
(5 \%)\end{array}$ & $\begin{array}{c}51 \\
(5 \%)\end{array}$ & $\begin{array}{c}56 \\
(3 \%)\end{array}$ & $\begin{array}{c}54 \\
(5 \%)\end{array}$ & $\begin{array}{c}55 \\
(4 \%)\end{array}$ & $\begin{array}{c}55 \\
(4 \%)\end{array}$ \\
\hline MaxI & (cm/day) & $\begin{array}{c}0.31 \\
(31 \%)\end{array}$ & $\begin{array}{c}0.36 \\
(51 \%)\end{array}$ & $\begin{array}{c}0.39 \\
(49 \%)\end{array}$ & $\begin{array}{c}0.40 \\
(23 \%)\end{array}$ & $\begin{array}{c}0.38 \\
(34 \%)\end{array}$ & $\begin{array}{c}0.42 \\
(35 \%)\end{array}$ & $\begin{array}{c}0.34 \\
(44 \%)\end{array}$ & $\begin{array}{c}0.28 \\
(43 \%)\end{array}$ \\
\hline $\mathrm{TF}$ & (days) & $\begin{array}{l}185.2 \\
(7 \%)\end{array}$ & $\begin{array}{c}190.8 \\
(12 \%)\end{array}$ & $\begin{array}{l}186.1 \\
(8 \%)\end{array}$ & $\begin{array}{l}184.2 \\
(8 \%)\end{array}$ & $\begin{array}{l}189.9 \\
(4 \%)\end{array}$ & $\begin{array}{l}188.3 \\
(9 \%)\end{array}$ & $\begin{array}{l}186.1 \\
(8 \%)\end{array}$ & $\begin{array}{r}178.6 \\
(10 \%)\end{array}$ \\
\hline DU & (days) & $\begin{array}{c}128.4 \\
(10 \%)\end{array}$ & $\begin{array}{c}101.8 \\
(33 \%)\end{array}$ & $\begin{array}{c}109.1 \\
(22 \%)\end{array}$ & $\begin{array}{c}125.9 \\
(15 \%)\end{array}$ & $\begin{array}{c}99.7 \\
(15 \%)\end{array}$ & $\begin{array}{c}111.8 \\
(21 \%)\end{array}$ & $\begin{array}{c}100.1 \\
(24 \%)\end{array}$ & $\begin{array}{r}101.0 \\
(19 \%)\end{array}$ \\
\hline
\end{tabular}

$(\mathrm{T} 0, \mathrm{TF}=$ dates when $5 \%, 95 \%$ respectively of total shoot length increment is achieved, (in days since April 1), TI = date when the growth rate is maximum, (in days since April 1), DU = TF-T0 $=$ total number of days of shoot elongation, MaxI = maximum rate of elongation, $\mathrm{LRI}=$ relative length of shoot achieved at date TI).

Table III.b. - Means of traits characteristics per taxa: experiment 2 (coefficient of variation between brackets, in bold, when the pure species is significantly different from hybrid at $5 \%$ ).

\begin{tabular}{|c|c|c|c|c|c|c|c|}
\hline \multirow{2}{*}{\multicolumn{2}{|c|}{ Seed orchard }} & \multicolumn{2}{|c|}{ SO7 } & \multicolumn{2}{|c|}{ SO9 } & \multicolumn{2}{|c|}{ SO10 } \\
\hline & & EL & HL & $\mathbf{E L}$ & HL & EL & HL \\
\hline T0 & (days) & $\begin{array}{c}57.6 \\
(21 \%)\end{array}$ & $\begin{array}{c}82.7 \\
(10 \%)\end{array}$ & $\begin{array}{c}67.5 \\
(10 \%)\end{array}$ & $\begin{array}{c}84.3 \\
(10 \%)\end{array}$ & $\begin{array}{c}64.7 \\
(16 \%)\end{array}$ & $\begin{array}{c}82.4 \\
(13 \%)\end{array}$ \\
\hline TI & (days) & $\begin{array}{c}112.6 \\
(15 \%)\end{array}$ & $\begin{array}{l}139.4 \\
(5 \%)\end{array}$ & $\begin{array}{l}133.6 \\
(5 \%)\end{array}$ & $\begin{array}{l}141.2 \\
(6 \%)\end{array}$ & $\begin{array}{l}131.2 \\
(5 \%)\end{array}$ & $\begin{array}{l}143.9 \\
(7 \%)\end{array}$ \\
\hline LRI & $\%$ & $\begin{array}{c}53 \\
(4 \%)\end{array}$ & $\begin{array}{c}55 \\
(2 \%)\end{array}$ & $\begin{array}{c}52 \\
(3 \%)\end{array}$ & $\begin{array}{c}56 \\
(2 \%)\end{array}$ & $\begin{array}{c}52 \\
(6 \%)\end{array}$ & $\begin{array}{c}55 \\
(3 \%)\end{array}$ \\
\hline MaxI & (cm/day) & $\begin{array}{c}0.45 \\
(35 \%)\end{array}$ & $\begin{array}{c}0.67 \\
(25 \%)\end{array}$ & $\begin{array}{c}0.47 \\
(36 \%)\end{array}$ & $\begin{array}{c}0.74 \\
(28 \%)\end{array}$ & $\begin{array}{c}0.29 \\
(31 \%)\end{array}$ & $\begin{array}{c}0.59 \\
(29 \%)\end{array}$ \\
\hline $\mathrm{TF}$ & (days) & $\begin{array}{l}161.0 \\
(15 \%)\end{array}$ & $\begin{array}{l}179.3 \\
(4 \%)\end{array}$ & $\begin{array}{l}191.8 \\
(7 \%)\end{array}$ & $\begin{array}{l}180.8 \\
(5 \%)\end{array}$ & $\begin{array}{l}194.2 \\
(7 \%)\end{array}$ & $\begin{array}{l}189.4 \\
(6 \%)\end{array}$ \\
\hline DU & (days) & $\begin{array}{c}103.4 \\
(21 \%)\end{array}$ & $\begin{array}{c}96.6 \\
(11 \%) \\
\end{array}$ & $\begin{array}{c}124.3 \\
(13 \%)\end{array}$ & $\begin{array}{c}96.5 \\
(11 \%) \\
\end{array}$ & $\begin{array}{c}129.4 \\
(18 \%) \\
\end{array}$ & $\begin{array}{r}107.0 \\
(12 \%) \\
\end{array}$ \\
\hline \multicolumn{8}{|c|}{ Seed collected on JL } \\
\hline \multicolumn{2}{|c|}{ Seed orchard } & \multicolumn{2}{|c|}{ SO2.3 } & \multicolumn{2}{|c|}{ SO6 } & \multicolumn{2}{|c|}{ SO8 } \\
\hline & & $\mathbf{J L}$ & HL & $\mathbf{J L}$ & HL & $\mathbf{J L}$ & HL \\
\hline T0 & (days) & $\begin{array}{c}85.7 \\
(11 \%)\end{array}$ & $\begin{array}{c}79.3 \\
(9 \%)\end{array}$ & $\begin{array}{c}81.2 \\
(9 \%)\end{array}$ & $\begin{array}{c}71.4 \\
(14 \%)\end{array}$ & $\begin{array}{c}76.4 \\
(12 \%)\end{array}$ & $\begin{array}{c}75.7 \\
(15 \%)\end{array}$ \\
\hline TI & (days) & $\begin{array}{l}142.2 \\
(6 \%)\end{array}$ & $\begin{array}{l}140.0 \\
(4 \%)\end{array}$ & $\begin{array}{l}139.7 \\
(4 \%)\end{array}$ & $\begin{array}{l}130.4 \\
(8 \%)\end{array}$ & $\begin{array}{l}130.5 \\
(5 \%)\end{array}$ & $\begin{array}{l}128.8 \\
(13 \%)\end{array}$ \\
\hline LRI & $\%$ & $\begin{array}{c}56 \\
(3 \%)\end{array}$ & $\begin{array}{c}55 \\
(2 \%)\end{array}$ & $\begin{array}{c}55 \\
(2 \%)\end{array}$ & $\begin{array}{c}54 \\
(2 \%)\end{array}$ & $\begin{array}{c}55 \\
(3 \%)\end{array}$ & $\begin{array}{c}55 \\
(2 \%)\end{array}$ \\
\hline MaxI & (cm/day) & $\begin{array}{c}0.65 \\
(28 \%)\end{array}$ & $\begin{array}{c}0.73 \\
(21 \%)\end{array}$ & $\begin{array}{c}0.78 \\
(23 \%)\end{array}$ & $\begin{array}{c}0.74 \\
(17 \%)\end{array}$ & $\begin{array}{c}0.38 \\
(43 \%)\end{array}$ & $\begin{array}{c}0.69 \\
(22 \%)\end{array}$ \\
\hline $\mathrm{TF}$ & (days) & $\begin{array}{l}181.3 \\
(4 \%)\end{array}$ & $\begin{array}{l}185.1 \\
(4 \%)\end{array}$ & $\begin{array}{l}181.6 \\
(3 \%)\end{array}$ & $\begin{array}{l}176.3 \\
(6 \%)\end{array}$ & $\begin{array}{l}169.4 \\
(5 \%)\end{array}$ & $\begin{array}{c}166.3 \\
(13 \%)\end{array}$ \\
\hline DU & (days) & $\begin{array}{c}95.6 \\
(12 \%)\end{array}$ & $\begin{array}{c}105.8 \\
(11 \%)\end{array}$ & $\begin{array}{l}100.4 \\
(8 \%)\end{array}$ & $\begin{array}{l}104.9 \\
(8 \%)\end{array}$ & $\begin{array}{c}92.9 \\
(14 \%)\end{array}$ & $\begin{array}{c}90.5 \\
(16 \%)\end{array}$ \\
\hline
\end{tabular}

$(\mathrm{T} 0, \mathrm{TF}=$ dates when $5 \%, 95 \%$ respectively of total shoot length increment is achieved, (in days since April 1), TI = date when the growth rate is maximum, (in days since April 1), DU = TF-T0 $=$ total number of days of shoot elongation, $\mathrm{MaxI}=$ maximum rate of elongation, $\mathrm{LRI}=$ relative length of shoot achieved at date TI). 
During the first weeks of growth (up to at least 115 days), differences with EL were usually small, either positive or negative according to orchards but not significantly different. They increased then in favour of HL more or less rapidly and globally more rapidly in experiment 2 than in experiment 1 . In both experiments and for nearly all orchards, a peak showing significant differences among taxa was reached at around 166 days from April 1 (about mid-September). It corresponded for many orchards to the maximum current daily growth increment. Differences decreased afterwards but they remained positive until the end of the growing season.

While the trends over days were quite consistent among orchards and years for the growth differences between HL and EL, they were less clear between HL and JL. Responses varied much according to orchards. For some orchards, no significant differences in growth were observed between taxa over the whole growing season (SO2.1 in experiment 1), or until about 160 days (SO5, SO2.2 in experiment 1, S06 in experiment 2); afterwards differences could be either positive (SO2.2, SO2.3) or negative (SO5, SO6). The SO8 orchard progeny in experiment 2 reacted differently: growth differences were positive and significant from the beginning and increased up to day 160.

\section{Hybrid vigour over European larch for growth traits}

In both experiments at the end of the second year, hybrid larch was consistently superior to European larch for nearly all traits and in nearly all orchard progenies. The differences between taxa were always statistically significant in experiment 2 and in most cases for experiment 1 except for the SO2 orchard (Table IVa).

In experiment 1 , hybrid vigour over EL was always positive and high for volume index as it ranged from +12.2 up to $+193.7 \%$. For diameter, it ranged from $+3.1-+53.1 \%$ and for total height from $-2.5-+43.5 \%$. It was always the weakest in SO2 orchard and the highest in SO3 orchard (Figure 3 and Table IVa).

In experiment 2 , hybrid vigour was consistently positive for all traits and much higher than in experiment 1. For volume index, it ranged from $+89.2 \%$ for SO9 orchard up to $+164.1 \%$ for SO10 orchard; for diameter, from +28.6 to $+37.2 \%$ and for total height from +30.9 up to $+62.0 \%$.

For $2^{\text {nd }}$ year shoot increment, hybrid vigour over EL was in the same range than for total height: $-11.1-+43.0 \%$ in experiment 1 and $+28.7-+63.4 \%$ in experiment 2 .

\section{Hybrid vigour over Japanese larch}

Except for SO5 orchard, the hybrid was more vigorous than the Japanese larch (Table IVb, Figure 3). But while differences among taxa were statistically significant for most orchards in experiment 2 whatever the traits, nearly no significant differences could be found between hybrid and Japanese larch in experiment 1.
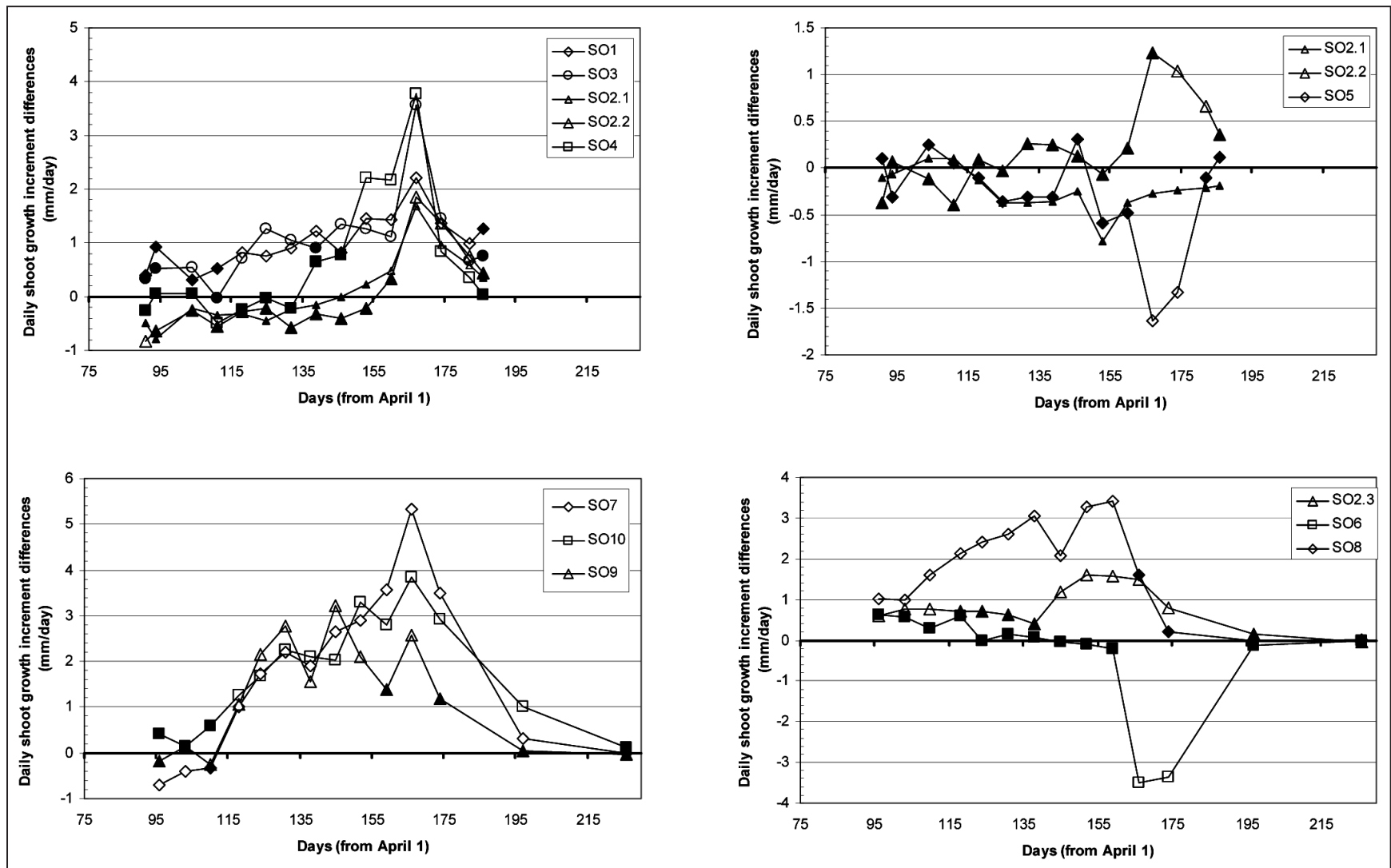

Figure 2. - Current daily shoot growth increment differences (mm/day) among hybrids and, European larch (left) and Japanese larch (right) during the $2^{\text {nd }}$ growing season in experiments 1 (up) and 2 (down) (Black dots indicate non-significant differences (at $5 \%$ level) among taxa). 


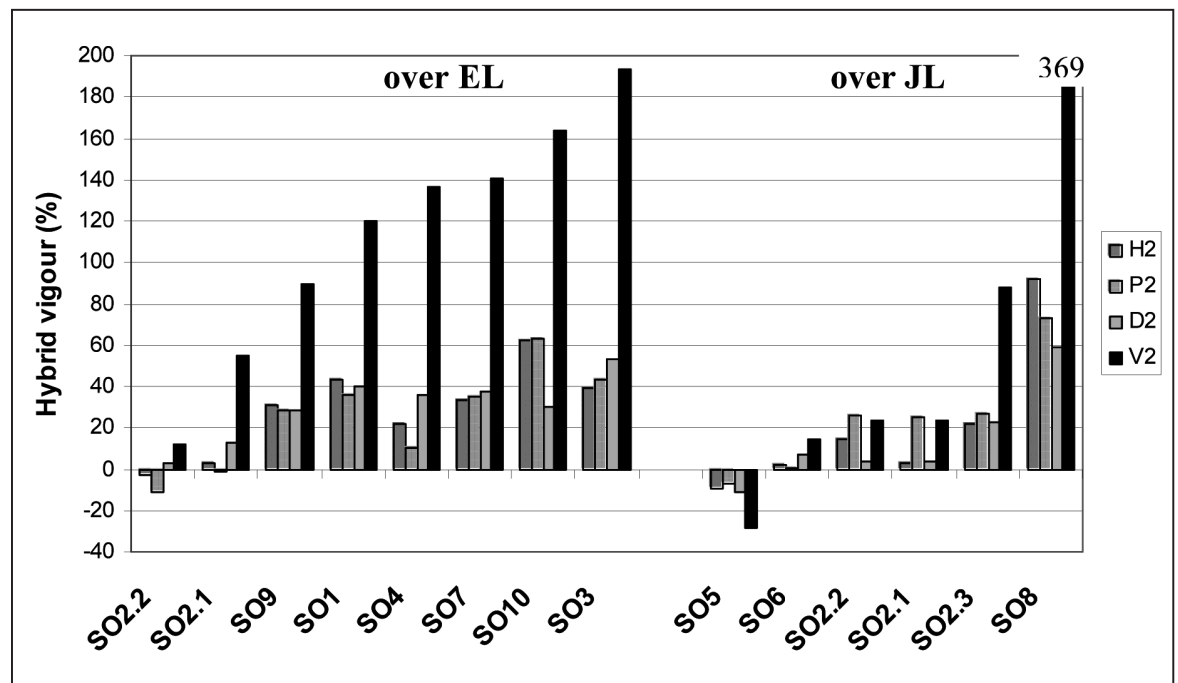

Figure 3. - Hybrid vigour over European larch (EL) and Japanese larch (JL) for growth traits.

Table IV.a and IV.b. - Heterosis (He) over a) European larch and b) Japanese larch (expressed in absolute and relative values; in bold, when heterosis is significant at $5 \%$ ).

a)

\begin{tabular}{|c|c|c|c|c|c|c|c|c|c|c|c|}
\hline & & $\mathbf{H e}$ & $\begin{array}{c}\mathrm{He} \\
(\%)\end{array}$ & He & $\begin{array}{c}\mathrm{He} \\
(\%)\end{array}$ & $\mathrm{He}$ & $\begin{array}{c}\mathrm{He} \\
(\%)\end{array}$ & $\mathrm{He}$ & $\begin{array}{l}\mathrm{He} \\
(\%)\end{array}$ & $\mathrm{He}$ & $\begin{array}{c}\mathrm{He} \\
(\%)\end{array}$ \\
\hline Experiment 1 & & \multicolumn{2}{|c|}{ SO1 } & \multicolumn{2}{|c|}{ SO2.1 } & \multicolumn{2}{|c|}{ SO2.2 } & \multicolumn{2}{|c|}{ SO3 } & \multicolumn{2}{|c|}{ SO4 } \\
\hline Total height & $\mathrm{cm}$ & 15.6 & 43.5 & 1.3 & 2.5 & -1.6 & -2.5 & 13.7 & 39.2 & 10.1 & 22.2 \\
\hline $\begin{array}{l}\text { Shoot length } \\
\text { increment }\end{array}$ & $\mathrm{cm}$ & 7.7 & 36.1 & -0.3 & -1.1 & -4.1 & -11.1 & 8.7 & 43.0 & 2.7 & 10.2 \\
\hline Diameter & $\mathrm{mm}$ & 39.7 & 40.2 & 14.0 & 12.4 & 4.0 & 3.1 & 38.6 & 53.1 & 33.6 & 36.2 \\
\hline Volume & $\mathrm{cm}^{3}$ & 48.8 & 119.8 & 31.0 & 54.7 & 11.1 & 12.2 & 35.2 & 193.7 & 49.2 & 136.8 \\
\hline Experiment 2 & & \multicolumn{2}{|c|}{ SO7 } & \multicolumn{2}{|c|}{ SO9 } & \multicolumn{2}{|c|}{ SO10 } & & & & \\
\hline Total height & $\mathrm{cm}$ & 15.7 & 33.7 & 16.6 & 30.9 & 22.5 & 62.0 & & & & \\
\hline $\begin{array}{l}\text { Shoot length } \\
\text { increment }\end{array}$ & $\mathrm{cm}$ & 12.7 & 35.1 & 12.4 & 28.7 & 18.2 & 63.4 & & & & \\
\hline Diameter & $\mathrm{mm}$ & 3.6 & 37.2 & 3.1 & 28.6 & 2.9 & 30.0 & & & & \\
\hline Volume & $\mathrm{cm}^{3}$ & 56.6 & 140.4 & 54.9 & 89.2 & 48.6 & 164.1 & & & & \\
\hline
\end{tabular}

b)

\begin{tabular}{|c|c|c|c|c|c|c|c|}
\hline & & $\mathrm{He}$ & He (\%) & $\mathrm{He}$ & Нe (\%) & $\mathrm{He}$ & He (\%) \\
\hline Experiment 1 & & \multicolumn{2}{|c|}{ SO2.1 } & \multicolumn{2}{|c|}{ S02.2 } & \multicolumn{2}{|c|}{ SO5 } \\
\hline Total height & $\mathrm{cm}$ & 1.6 & 3.2 & 8.2 & 14.7 & -4.1 & -9.3 \\
\hline $\begin{array}{l}\text { Shoot length } \\
\text { increment }\end{array}$ & $\mathrm{cm}$ & 5.7 & 24.8 & 6.8 & 26.3 & -1.5 & -7.1 \\
\hline Diameter & $\mathrm{mm}$ & 4.1 & 3.4 & 4.6 & 3.6 & -12.2 & -10.8 \\
\hline Volume & $\mathrm{cm}^{3}$ & 16.5 & 23.1 & 19.2 & 23.1 & -16.3 & -28.7 \\
\hline Experiment 2 & & \multicolumn{2}{|c|}{ SO2.3 } & \multicolumn{2}{|c|}{ SO6 } & \multicolumn{2}{|c|}{ SO8 } \\
\hline Total height & $\mathrm{cm}$ & 13.1 & 22.2 & 1.9 & 2.4 & 30.4 & 91.6 \\
\hline $\begin{array}{l}\text { Shoot length } \\
\text { increment }\end{array}$ & $\mathrm{cm}$ & 12.5 & 26.8 & 0.2 & 0.3 & 20.0 & 72.7 \\
\hline Diameter & $\mathrm{mm}$ & 2.6 & 22.7 & 1.0 & 6.6 & 5.1 & 59.1 \\
\hline Volume & $\mathrm{cm}^{3}$ & 61.9 & 87.6 & 22.2 & 14.6 & 89.1 & 369.2 \\
\hline
\end{tabular}

In experiment 1 , hybrid vigour over JL was much weaker than over EL for all traits. It remained positive for all traits in $\mathrm{SO} 2$ orchard with the highest superiority found for volume index (around $+23 \%$ over JL). For SO5 orchard, it was consistently negative whatever the trait. Hybrid vigour for $2^{\text {nd }} \mathrm{yr}$ shoot length ranged from -7.1 and $+26.3 \%$. For SO2 orchard, it was much higher than for total height.
In experiment 2 , hybrid vigour over JL was always positive and much higher than over EL. It ranged from +14.6 to $+369.2 \%$ for volume index, from +6.6 to $+59.1 \%$ for diameter and from +2.4 to $+91.6 \%$ for total height. For $2^{\text {nd }}$ yr shoot length, it was in the same range as for total height: $+0.3-+72.7 \%$. The highest values were found for SO8 and the lowest for SO6 orchards. 


\section{Discussion}

\section{Validity of the method}

The use of open-pollinated progenies from interspecific hybridisation seed orchards provided a simple way to compare intra- and inter-specific progenies from related pedigrees, which is necessary for the study of hybrid vigour. This approach is valid insofar diagnostic markers are available and reliable to retrospectively identify taxa in a mixed progeny. From an economical point of view, it could be justified when extra-costs for implementing markers on individual plants are exceeded by costs for controlled crossing to create adequate mating designs like diallels. For larch, this approach is attractive because on one side, efficient diagnostic molecular markers are available (ACHERÉ et al., 2004; GROS-LOUIS et al., 2005) and reliable in the context of first-generation hybrids (problems might occur when F2's are present in seed orchard progenies for any reasons, see PÂQUES et al., 2006) and on the other side, due to the low fecundity in larch and thereby the rather weak success of controlled crosses in our environmental conditions (PÂQUES, 1994), factorial/diallel designs are costly to create and very much time-consuming.

Yet, one might argue that this approach did not let us express heterosis in its classical forms, i.e. as the superiority of hybrids either over their mid-parent value or over their best parent (FALCONER, 1982). Instead, because of the lack of either one of the two parental progenies, we had to restrict the comparison in most cases to only one parental species, varying according to orchards. In any cases, the use of different types of orchards using either the European or the Japanese larch as the mother offered us the possibility to compare overall hybrids to both parental species.

For some seed orchards which have only one clone as mother (e.g. SO1, SO3, SO7, SO8, SO9, SO10), the nature of their intra-specific progenies to which hybrids were compared, raised question. Indeed, these could be the result of either selfing or of outcrossing by polluting pollens from outside the orchards or of both. If selfing were predominant, one consequence would be an overexpression of hybrid superiority due to inbreeding depression in the parental progeny. We had unfortunately no way to quantify this aspect. Yet, our experience with selfing based on artificial pollination let us think that the probability to have selfs must be weak. Indeed, selfing in larch induces extremely low filled seed set and low germination and survival rates (PÂQUES, 1994). We favoured therefore the possibility of outcrossing by polluting pollen from neighbourhood trees but this hypothesis should be checked.

\section{Level of heterosis}

Superiority over either one of the two parental species was not a priori obvious in nursery conditions, particularly favourable for plant growth. Clearly across experiments, hybrid vigour over JL was on average lower than that over European larch: the overall mean hybrid superiority for volume index reached $+77 \%$ over JL compared to $+114 \%$ over EL. As well for volume growth components, total height and diameter, superiority over
JL was also globally lower than over EL: $+20.8 \%$ vs $+28.9 \%$ for height and $+14.1 \%$ vs $+30.1 \%$ for diameter.

For total height which is the most commonly studied growth trait in the literature, our results were in the range of known results for hybrid superiority. A literature survey on hybrid superiority for total height from age 2 to 39 (PÂQUES, 2002) indicated a superiority of hybrids in the range of $-5 \%$ up to $+58 \%$ over EL and of $+0.5 \%$ to $+35 \%$ over JL. But, no clear trends could confirm a lower superiority of hybrids over JL than over EL. In a more recent study of heterosis based on a inter-/intra-factorial mating design, PÂQUES (2002) found a global hybrid vigour much greater over JL (over $+26 \%$ ) than over EL (less than 1\%) for total height at age 2 . The genetic background of the parental species genitors together with the environmental conditions might explain these contrasting results as we will show.

Overall levels of hybrid superiority were also quite different between experiments. They were globally higher in experiment 2 than in experiment 1: for example, for volume index, hybrid vigour reached on average $+131.2 \%$ over EL and $+157.1 \%$ over JL in experiment 2 compared to $+103.4 \%$ and only $+5.8 \%$ respectively in experiment 1 . Growth conditions in experiment 2 were globally more favourable than in experiment 1 as expressed by better mean growth performances (Tables II $a$ and $b$ ) and by the larger average contribution of $2^{\text {nd }}$ growth season increment to total height (79\% compared to $54 \%$ ). Better ecological and/or cultivation conditions yet undetermined - seemed thus to induce higher levels of heterosis: they seem to favour the growth of the hybrids over that of both parental species and especially over that of the Japanese larch as shown by the greater superiority differential over experiments for JL. Similar results were found by $\mathrm{LI}$ and WU (1997) for Aspen hybrids (Populus tremuloides x P. tremula) which better expressed their superiority over their parents on a farmland site (most fertile soil) than on a forest site, and by KAIN (2003) for Pinus elliottii var. elliottii x Pinus caribaea var. hondurensis hybrids.

This 'overall' heterosis hid in fact quite contrasting situations at individual orchard levels. Among orchard progenies, heterosis over both EL and JL was highly variable whatever the traits. As an example, for volume index the superiority over EL varied between $+12.2 \%$ and $+193.7 \%$ according to orchards ; over JL, it ranged from +14.6 and $+369.2 \%$. Interestingly excepted for one orchard, it was always positive. For height and diameter, not only the level of heterosis was highly variable among orchards but also their relative magnitude (and thereby their contribution to volume heterosis): according to orchards, heterosis for total height could be lower, equal or higher than for diameter. Within more uniform genetic backgrounds, heterosis for stem diameter is frequently greater than for total height (PÂQUES, 2002; KAIN, 2003)

The high variability observed among orchards was most probably due to the various genetic backgrounds of the genitors, namely the origins of parent clones, the number of clones involved as female and male parents and their level of selection. An additional reason could 
be found in seed orchard SO5. As revealed in Pâques et al. (2006), some unknown number of seedlings examined in this study and molecularly identified as pure JL would be in fact backcrosses of type (JLxEL)xJL. Indeed, a molecular check of SO5 parental clones revealed that some of them were in fact hybrids of type JLxEL. A similar situation is also hypothesised for the SO6 orchard which was established with parental clones selected in the same context. This mixture of taxa could of course lead to imprecise results and it might explain the lowest levels of heterosis found for SO5 and SO6 as well as their distinct features like for current daily shoot growth increments (figure 2).

For those reasons, comparison of growth behaviour and of related growth components among taxa should be better restricted within orchards.

\section{Contribution of growth phenology and growth rhythm parameters to heterosis for total height}

The final length of annual terminal shoots and thereby of total height is a function of the meristematic activity which is influenced by both intrinsic (genetic and physiological) and extrinsic (environmental) factors and their interaction. The start and cessation of growth, and therefore its total duration, may have a direct impact on total shoot growth together with the growth rhythm during the growing season. Convenient parameters to characterize the latter include the mean daily growth increment, the maximum rate of growth increment but also the current daily growth increments which allow following up growth rhythm all along the growing season.

Genetic differentiation among species and even among populations within species for growth phenology and growth rhythm parameters has been observed for various conifers including e.g. Larix (FARMER et al., 1993; Baltunis and Greenwood, 1999), Pinus sylvestris (Mikola, 1985), Pinus ponderosa (REHFEldt, 1992), Picea abies (Skroppa and Magnussen, 1993). Contrasting results have been found according to species and populations in the relative weight of phenology and growth parameters to total growth. For several Larix species, BALTUnis and GreEnwood (1999) found that total height was positively correlated with the date of cessation of shoot growth and the total duration of growth but not with the time of shoot initiation and with the rate of elongation. In some other studies (MCCRADY and JOKELA, 1996; EMHART et al., 2006), no significant differences could be found for these growth phenology parameters among families or even among species probably due to a more restricted origin of their genetic material.

The overall positive heterosis observed in this study for shoot elongation and more generally speaking for height growth, was obviously differently linked to phenology and growth rhythm parameters whether it was expressed over EL or JL. The date of growth start, the total duration of growth, the date of maximum growth rate and the maximum rate of elongation seemed to be key-parameters in explaining growth superiority of hybrids over EL and much more important than the date of cessation of growth. Over JL, not only the date of growth cessation did not look much relevant in relation with heterosis but also neither the total duration of growth nor the maximum rate of elongation. Only the date of growth start and the date of maximum growth rate significantly differed between HL and JL.

For all 8 orchards, hybrid progenies consistently started their growth significantly later than EL, had a delayed growth rate maximum and a shorter duration of growth. While the duration of growth is usually considered as a main component of total growth (KOSKI and SiEvANEN, 1985), HL progenies in our study surprisingly succeeded to achieve a much bigger height increment during a neatly shorter growing season than EL. This clearly greater growth efficiency of hybrids over EL can be seen through their higher mean daily shoot growth increment and their higher maximum rate of shoot elongation. A better matching of their growth period with more favourable climatic and eco-pedological conditions during the growing season is hypothesised to contribute to this hybrid efficiency over its parents together with some other features such as a more favourable branching pattern and needle density as already observed by MATYSSEK and Schulze (1987b) on old trees. This relationship with ecological parameters needs to be further investigated.

Hybrid vigour over JL was seen to be positive or negative and much more related to some given orchard parameters. When it was observed positive, hybrid vigour was apparently linked to diverse favourable combinations of some hybrid characteristics: earlier growth start, earlier reach of their maximum rate of elongation, later growth cessation, longer growth duration and for some progenies, greater maximum rate of elongation.

As it can be seen, our results are mostly in contradiction with BALTUNIS and GREENWOOD (1999)'s conclusions. Indeed they attributed the superiority of $L$. decidua $\mathrm{x}$ L. kaempferi hybrids (and of their reciprocal) over EL to a later cessation of growth for hybrids together with a longer growth duration. In contrast, they did not observe any differences for the date of growth start and for the rate of elongation. Differences in the genetic background (origin of the parental species), in the pedigree (hybrids related to parental species or not), in the ecological conditions (oceanic in this study vs a mountainous climate) and in the age of trees might explain these different results. The methodology used for growth assessment was also much different: while we measured growth on terminal shoots, BALTUNIS and GREENWOOD (1999) recorded growth on lateral shoots at breast height using fixed measures to determine growth start and cessation. Whereas they noted the good link between the total elongation of the lateral shoots and the height annual increment, it is not sure that the lateral and the terminal shoots follow similar growth rhythm. Indeed, it is already well-known that flushing in larches moved acropetally and centrifugally and that the timing for terminal shoot buds flushing is several days up to several weeks later than for basal lateral shoots. This should be investigated for shoot elongation. 
These synthetic phenological and growth parameters may hide in fact different growth 'strategies' among taxa (i.e. hybrids and their related parents in this study) and thus ways by which heterosis is built up over the growing season. Indeed as shown by EMHART et al. (2006), the significant differences observed in basal area size among two pine species (Pinus taeda and P. elliottii) were explained by differential growth rates expressed only during short, discrete time periods. In fact, a more detailed look on growth rhythms in our study (such as plotted in Figure 2) revealed contrasting situations for expression of hybrid vigour over the growing season. For some hybrid progenies (e.g. SO1, SO3), their superiority over EL was linked to a sum of nearly continuously significantly higher current daily growth increments. For some others like SO4, hybrid superiority started to build up much later thanks to late vigorous current daily growth increments. For SO2 curiously, significantly higher current increments occurred only during a very short period but they were not sufficient for allowing expression of positive hybrid vigour. Obviously for all orchards, the very early growth period (up to more or less day 115) and the very late one did not benefit to hybrids and did not contribute much to hybrid superiority. Superiority over JL, when positive, looked also as the result of various growth rhythms along the season: for example in experiment 2 , heterosis built up very early and progressively for SO8 orchard; it built up much more lately for SO2.

\section{Conclusions}

Variable levels of heterosis have been observed. Their sources of variation include the different genetic backgrounds of the parents involved in the orchard progenies, the species over which superiority is evaluated, environmental conditions (year) and the traits considered.

While significant and consistent differences have been observed between hybrid progenies and their related EL progenies for phenological growth traits, a better timing of growth rhythm over the growing season together with a greater growth efficiency during that growth period as seen through higher mean daily shoot growth increment and higher maximum rate of shoot elongation allowed for a consistently positive heterosis of hybrids over EL. The situation appeared more complex with JL as heterosis could be positive or negative according to orchards. Superiority of hybrids over JL could be the result of a partial combination of either a longer duration of growth or a better timing of growth within the vegetation period, or a higher rate of elongation.

Besides the high variation in heterosis levels for height growth observed among orchard progenies, the way heterosis was built up over the growing season could also be very variable: the growth superiority of the hybrids could be the result of a cumulative constant superiority of growth rhythms along the growing season or of greater growth rates during discrete periods of time with a peak towards the end of the growing season.

A common genetic background for parents of each species together with related inter-and intra-specific progenies from both parents such as can be found in diallel/factorial mating designs, would help us getting even more insight in our understanding of the genetic and physiological basis of heterosis in larch. In addition to phenological and growth rhythm parameters, other morphological traits such as branching patterns and needles size and distribution should also be investigated as contributors to hybrid vigour.

Finally, this study stresses also the importance of validating seedlings and trees taxa when studying heterosis and therefore, of developing reliable molecular and/or morphological diagnostic markers.

\section{Acknowledgments}

We acknowledge the two anonymous reviewers for their pertinent comments and help to further improve this manuscript. Financial support for this research was provided by the French Ministry of Agriculture (grant 10C02-61.21.43-MelHyb). Special thanks to the INRAOrléans Experimental Unit team for field trials establishment and field measurements and to C. BURET for taxa identification through molecular markers.

\section{References}

Acheré, V., P. Faivre Rampant, V. Benoit, J. C. Leplé., L. E. PÂQUES and D. PRAT (2002): Characterization of hybrids between Larix decidua and L. kaempferi by molecular markers, pp. 176-186. In: Proc. Improvement of larch (Larix sp) for better growth, stem form and wood quality, Larix 2002: Gap, September 16-21, 2002, edited by INRA, Orléans.

Acheré, V., P. Faivre Rampant, L. E. PÂques and D. Prat (2004): Chloroplast and mitochondrial molecular tests identify European x Japanese larch hybrids. Theor. Appl. Genet. 108: 1643-1649.

BALtunis, B. S. and M. S. GReEnwood (1999): Variation in lateral shoots elongation patterns and hybrid vigor in full-sib families and interspecific hybrids of larch. Tree Physiology 19: 131-136.

Bonnet-Masimbert, M., P. Baldet, L. E. PÂques and G. PhILIPPe (1998): From flowering to artificial pollination in larch for breeding and seed orchard production. For.Chron. 74 (2): 195-202.

Emhart, V. I., T. A. Martin, T. L. White and D. A. Huber (2006): Genetic variation in basal area increment phenology and its correlation with growth rate in loblolly and slash pine families and clones. Can. J. For. Res. 36: 961-971.

FALCONER, D. S. (1982): Introduction to quantitative genetics. Longman, London.

Farmer, R. E., G. O'Reilly and D. Shaotang (1993): Genetic variation in juvenile growth of tamarack (Larix laricina) in northwestern Ontario. Can. J. For. Res. 23: 1852-1862.

Gros-Louis, M. C., J. Bousquet, L. E. PÂques and N. ISABEL (2005): Species-diagnostic markers in Larix spp. based on RAPDs and nuclear, cpDNA, and mtDNA gene sequences, and their phylogenetic implications. Tree Genetics \& Genomes 1 (2): 50-63.

KaIN, D. P. (2003): Genetic parameters and improvement strategies for the Pinus elliottii var. elliottii x Pinus caribaea var. hondurensis hybrid in Queensland, Australia. PhD thesis, Australian National University, $361 \mathrm{pp}$. 
Koski, V. and R. Sievanen (1985): Timing of growth cessation in relations to the variations in the growing season, pp. 137-193. In: Crop Physiology of Forest Trees, edited by P. M. A. Tigerstedt, P. Puttonen and V. Koski. Univ. Helsinski, Dept. of Plant Breeding.

LI, B. and R. WU (1997): Heterosis and genotype $x$ environment interactions of juvenile aspens in two contrasting sites. Can. J. For. Res. 27: 1525-1537.

MatysseK, R. and E. D. Schulze (1987a): Heterosis in hybrid larch (Larix decidua $\mathrm{x}$ leptolepis). I. The role of leaf characteristics. Trees 1: 219-224.

MATYSSEK, R. and E. D. SCHUlZE (1987b): Heterosis in hybrid larch (Larix decidua x leptolepis). II. Growth characteristics. Trees 1: 225-231.

MCCRADY, R. L. and E. J. JokelA (1996): Growth phenology and crown structure of selected loblolly pine families planted at two spacings. For. Sci. 42: 46-57.

MiKolA, J. (1985): Relationships between height growth differences of Scots pine full-sib families and variation in seed size, annual growth rhythm, and some foliage characteristics, pp. 233-243. In: Crop Physiology of For- est Trees, edited by P. M. A. Tigerstedt, P. Puttonen and V. Koski. Univ. Helsinki, Dept. of Plant Breeding.

PÂQUES, L. E. (1994): Croisements contrôlés de mélèze: bilan des activités 1987-1994. INRA, document interne.

PÂQUES, L. E. (2002): Heterosis in interspecific hybrids between European and Japanese larch, pp. 155-163 in Proc. Improvement of larch (Larix $s p$ ) for better growth, stem form and wood quality, Larix 2002: Gap, September 16-21, 2002, edited by INRA, Orléans.

PÂques, L. E., G. PhilipPe and D. PRAT (2006): Identification of European and Japanese Larch and Their Interspecific Hybrid with Morphological Markers: Application to Young Seedlings. Silvae Genetica 55: 123-134.

REHFELDT, G. E. (1992): Early selection in Pinus ponderosa: compromises between growth potential and growth rhythm in developing breeding strategies. For. Sci. 38: 661-677.

Skroppa, T. and S. Magnussen (1993): Provenance variation in shoot growth components of Norway spruce. Silvae Genetica 42: 111-120.

\title{
Estimation of Clonal Variation in Seed Cone Production Over Time in a Scots pine (Pinus sylvestris L.) Seed Orchard
}

\author{
By J. Kroon ${ }^{1)}$, U. Wennström ${ }^{2)}$, F. Prescher ${ }^{3)}$, D. LindGren ${ }^{4)}$ and T. J. Mullin ${ }^{5)}$
}

(Received $17^{\text {th }}$ December 2007)

\begin{abstract}
Possibilities for early selection of clones for future seed cone production were studied in a clonal seed orchard of Scots pine (Pinus sylvestris L.) in northern Sweden over the first 30 years following establishment. The annual data were modelled as series of bivariate analyses. The correlations between cone production of clones in any individual year and that of a previous year, and cumulative cone production over all years were studied. The corresponding multivariate analysis for a full data fit simultaneously was best estimated

\footnotetext{
1) Corresponding author: JoHAN Kroon, Skogforsk, P.O. Box 3, SE-918 21 Sävar, Sweden. Phone +46 9020333 50. Fax: +46 9020333 60. E-Mail: johan.kroon@skogforsk.se

2) UlfSTAND WennSTRÖM, Skogforsk, P.O. Box 3, SE-918 21 Sävar, Sweden. E-Mail: ulfstand.wennstrom@skogforsk.se

3) Finnvid Prescher, Svenska Skogsplantor AB, Seed production, SE-340 14 Lagan, Sweden. E-Mail: finnvid.prescher@skogsplantor.se

4) DAg LindGren, Department of Forest Genetics and Plant Physiology, Swedish University of Agricultural Sciences, SE-901 83 Umeå, Sweden. E-Mail: dag.lindgren@genfys.slu.se

5) Tim J. Mullin, BioSylve Forest Science NZ Limited, 45 Korokoro Road, Lower Hutt 5012, New Zealand. E-Mail: tim. mullin@biosylve.com
}

with a genetic distance-based power model (AR). The genetic (variation among clones) and environmental variation were of the same magnitude. The genetic correlations were larger than the phenotypic correlations and both increased with orchard age. Basing selection of clones on a single observation at an early age to improve future cone production was not effective, but efficiency increased if cumulative cone count over many years was used. Year-to-year genetic correlations indicated that early forecasts by clone of cone production at mature ages are highly uncertain. Reliable predictions (moderate correlations) could be achieved only if based on rather mature grafts, 14 or more years after establishment.

Key words: Pinus sylvestris, fruitfulness, longitudinal data, reproductive competence, broad-sense heritability.

\section{Introduction}

Seed production is fundamental to the economy of seed orchards. One way to increase seed production is to select clones which are prolific seed producers. Seed production ability can then be weighed against breeding value when selecting clones (LINDGREN et al., 2004), provided a reliable forecast of future fertility is available. 